\title{
基于碎屑锆石形态学和热年代学特征解析天山 隆升过程
}

常健 ${ }^{1,2^{*}}$, 张应鳞 ${ }^{1,2}$, 邱楠生 ${ }^{1,2 \dagger}$, 李晨星 ${ }^{1,2}$

1. 中国石油大学(北京)油气资源与探测国家重点实验室, 北京 100249 ;

2. 中国石油大学(北京)地球科学学院, 北京 102249

* 通讯作者, E-mail: changjian@cup.edu.cn

†通讯作者, E-mail: qiunsh@cup.edu.cn

收稿日期: 2021-08-25; 收修改稿日期: 2021-11-16; 接受日期: 2021-11-23; 网络版发表日期: 2021-12-23

国家自然科学基金项目(批准号: 41972125、U19B6003-02-03)资助

\begin{abstract}
摘要中国西部天山山脉蕴含丰富的矿产资源, 然而与资源勘探密切相关的构造隆升史一直存在争议. 为了解决 这个科学问题, 文章创新性地综合沉积盆地碎屑锆石形态学特征和热年代学参数研究了天山南部早期构造隆升 过程. 库车前陆盆地中-新生界碎屑锆石形态以 $\mathrm{P} 、 \mathrm{~S} 、 \mathrm{G}$ 等3 种类型为主, 相应的平均碱度指数和平均温度指数分 别为668.0 677.2 和347.6 413.5. 结合270 330和380 470Ma两组碎屑锆石 U-Pb年龄, 揭示南天山及中天山南部出 露的早石炭世-早二叠世和中奥陶世-中泥盆世时期碱性花岗岩体是碎屑锆石的主要物质来源. 碎屑锆石裂变径迹 年龄重分组分析揭示, 库车前陆盆地中-新生界主要有中天山南部、南天山东部、南天山中部等3个物源区, 其中 南天山东部贡献量最多. 结合重分组ZFT年龄和时滞演化模式揭示, 南天山和中天山南部主要经历了泥盆纪、二 叠纪、中三叠世-中侏罗世、白严纪、中新世以来等5期隆升事件，分别与南天山洋向北俯冲至中天山深部、南 天山洋闭合后的挤压与增生、中-新生代㒸塘-拉萨-印度板块与欧亚板块南缘一系列碰撞等构造活动有关. 文章 提出新的物源分析方法, 并成功应用于天山地区, 为中亚地区构造演化研究开拓新思路.
\end{abstract}

关键词 天山, 库车前陆盆地, 物源分析, 锆石形态, 热年代学, 时滞演化

\section{1 引言}

由造山带产生的剥蚀物质经风能、河流等外营力 作用被快速搬运至毗邻前陆盆地坳陷区沉积下来，从 而使造山带隆升剥蚀过程与前陆盆地快速沉降作用呈 相互依存关系. 当磷灰石、锆石等矿物从造山带被剥 蚀搬运至沉积盆地后, 如果沉积埋藏深度很浅, 埋藏
温度未超过低温热年代学封闭温度体系, 那么这些矿 物保留的仍是物源区热年代学信息, 可有效地用于研 究物源区(造山带)隆升史和盆山耦合关系(Garver等, 1999; Bernet和Garver, 2005; Carrapa，2009; Qiu等, 2012). 通过对碎屑矿物未重置(unreset)低温热年代学 年龄重分组分析可初步识别物源区(造山带)及其隆升 期次, 而建立重分组低温热年代学年龄峰值年龄、地 
层年龄及时滞(Lag time)三者关系可研究造山带演化 阶段和剥蚀速率(Garver等，1999; Bernet和Garver, 2005; Carrapa, 2009), 该研究手段已成功应用于阿尔 卑斯山、青藏高原、台湾中央山脉等造山带的构造隆 升研究(Garver等, 1999; Bernet等, 2001; Bernet和Garver, 2005; Carrapa, 2009; Carrapa等, 2016; Malusà和 Fitzgerald, 2020).

与阿尔卑斯山、青藏高原等类似, 天山(尤其是天 山南部)长期处于隆升剥蚀状态, 其剥蚀物被快速搬运 到南侧的前陆盆地沉积下来, 因此在天山南侧库车前 陆盆地采集中-新生界碎屑岩开展热年代学物源分析 是可行的. 一些学者曾利用天山基岩区和库车前陆盆 地北缘中生界已重置的磷灰石裂变径迹和(U-Th)/He 年龄探讨过南天山晚期(白严纪以来)的构造隆升过程, 但仍存在争议(Yin等, 1998; Huang等, 2006; Wang等, 2009; Chang等, 2017, 2021). 另外, 早期研究借助碎屑 锆石 $\mathrm{U}-\mathrm{Pb}$ 、碎屑重矿物、全岩主元素等分析仅明确 了南天山是库车前陆盆地中-新生代的主要物源区 $(\mathrm{Li}$ 等，2004; 李双建等，2006; Li和Peng，2010; Liu等, 2013), 而碎屑沉积物中包含的其他地质信息未被提取 出来. 相较于以上研究手段, 库车前陆盆地中-新生界 未重置碎屑锆石裂变径迹年龄不仅可挖掘天山更早期 的构造演化史, 而且可为后期构造隆升期次提供新证 据, 从而更好地理解天山地区构造、地貌、剥蚀和沉 积之间的相互关系. 本次研究首先基于碎屑锆石形态 学特征和 $U-P b$ 年龄明确天山南部是库车前陆盆地中新生代主要的沉积物质供应区, 在此基础上通过对未 重置碎屑锆石裂变径迹年龄开展重分组和时滞演化模 式研究剖析物源区数量、隆升期次及剥蚀速率等, 最 后综合讨论了物源区的分布范围及多期隆升事件的主 控因素. 本文不仅提出了新的物源分析研究方法和首 次明确了南天山自碰撞形成以来的多期冷却事件, 而 且印证了碎屑热年代学物源分析在天山地区的应用成 效, 从而为中亚地区构造演化研究开拓了新思路.

\section{2 地质概况及样品信息}

本文研究区域包括天山南部和塔里木北部库车前 陆盆地. 天山是中亚巨型复合造山带的一部分, 南北两 侧分别被塔里木盆地和准噶尔盆地夹持. 区域上, 东西 向以乌鲁木齐-库尔勒一线为界, 将天山分为东天山和
西天山，而西天山又被划分为北天山、中天山、南天 山等三部分(图1a). 中天山是一条岩浆弧, 由奥陶纪石炭纪不同发育程度的火山岩及花岗岩组成(高俊等, 2009). 位于中天山南侧的南天山造山带随着中天山岛 弧与塔里木板块在晚石炭世-早二叠世的碰撞拼合而 开始发育(Xiao等, 2004; Han等, 2011; Ge等, 2012), 其 地层发育较全, 前寒武系、下古生界和上古生界分别 为浅变质岩系、海相火山-沉积建造及海陆交互相火 山-沉积建造(陈国达等, 1983).

库车前陆盆地位于塔里木盆地北部, 夹持于南天 山和塔北隆起之间, 由北到南可依次划分为北部单斜 带、克拉苏-依奇克里克背斜带、拜城凹陷、阳霞凹 陷、秋里塔格背斜带等 5 个次级构造带(图1b). 它是在 晚二叠世之前的古生代褶皱基底上经晚二叠世-三叠 纪前陆盆地、侏罗纪-古近纪伸展坳陷盆地及新近纪第四纪再生前陆盆地演化形成的(何光玉等, 2004; 何 登发等, 2009). 以古近系古新统-始新统库姆格列木组 膏盐岩层作为标志层, 可将库车前陆盆地地层划分为 盐下、盐层、盐上等三个层序(汤良杰等，2004). 其 中, 盐下层序主要由三叠系、侏罗系和下白严统组成, 主要沉积陆相砾岩、砂岩和泥岩; 盐岩层序为古近系 库姆格列木组, 主要岩性为灰白色、浅灰色盐岩、膏 岩、灰岩、泥灰岩、泥岩和砂岩、砂砾岩; 盐上层序 由渐新统-第四系陆相红色碎屑岩组成.

本次研究在库车前陆盆地东部牙哈剖面共采集了 6块碎屑岩露头样品, 层系涉及下侏罗统、下白严统、 古新统、渐新统、中新统及第四系, 样品位置及具体 信息见图1c和表1. 首先通过重矿物分选技术从采集的 样品中获取到本文所需的锆石矿物, 然后开展锆石形 态学、U-Pb年龄及裂变径迹年龄等测试与分析. 其中 锆石 $U-\mathrm{Pb}$ 和裂变径迹实验方法和测试结果见网络版 附录(http://earthen.scichina.com).

\section{3 库车前陆盆地中-新生界物源分析}

利用库车前陆盆地中-新生界样品的碎屑锆石裂 变径迹年龄及其时滞演化模式研究天山南部的构造隆 升过程, 首先需要明确这些层系的碎屑锆石来源于天 山. 如前所述, 人们曾通过分析砂岩骨架颗粒、全岩 主元素、碎屑重矿物等认为南天山自中生代以来一直 是库车前陆盆地最重要的物质供应区( $\mathrm{Li}$ 等, 2004; 李 

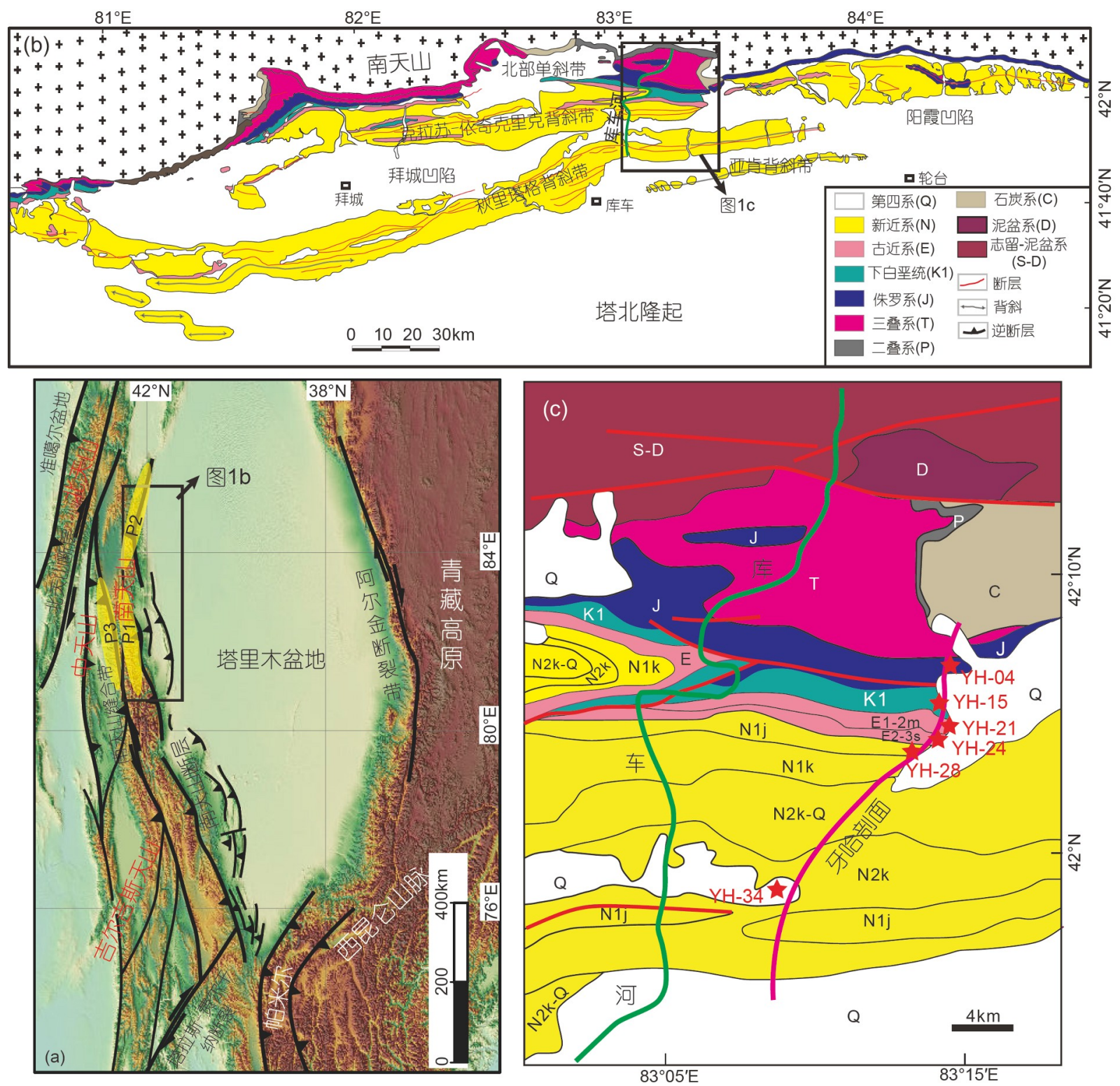

图 1 中亚地区地貌及主要断裂构造图(a)、库车前陆盆地地质图及构造分区(b)和牙哈剖面地质图(c)

(a) 黄色区域为本研究识别的三个物源区; (c) 红色五角星标注样品位置

双建等, 2006; Li和Peng, 2010). 为了进一步阐明库车 前陆盆地东部物质来源，我们结合锆石形态学特征和 $\mathrm{U}-\mathrm{Pb}$ 年龄对牙哈剖面中-新生界碎屑岩样品进行了细 致研究.

\section{1 碎屑锆石形态学特征}

锆石矿物在结晶过程中受岩浆化学成分、温度、 铝碱指数等的影响会发育不同的形态，同时其抗风化
和抗变质能力强，经风化搬运至盆地沉积后通常仍会 保存良好的原始形态. Pupin(1980)根据锆石晶体不同 柱面和雉面的组合关系及其发育程度将锆石形态划分 为 16 个主型和 64 种亚型, 并设计了锆石形态分布图(图 2). 其中，横坐标表示碱度指数(I.A)，纵坐标表示温度 指数 $(I . T)$. 这两种指数范围为 $100 \sim 800$, 均被 8 等分, 纵 坐标从上往下温度指数增加，而横坐标从左至右碱度 指数增加. 本研究对牙哈剖面中-新生界 6 个样品的 
表 1 库车前陆盆地牙哈剖面样品基本信息及碎屑锆石形态和裂变径迹参数测试结果

\begin{tabular}{|c|c|c|c|c|c|c|c|c|c|c|c|c|c|c|}
\hline 样品号 & $\begin{array}{l}\text { 地层年 } \\
\text { 龄(Ma) }\end{array}$ & 层位 & 岩性 & $\begin{array}{c}\text { 海拔 } \\
(\mathrm{m})\end{array}$ & 经纬度 & $I . \bar{A}^{\mathrm{a})}$ & $I . \bar{T}^{\mathrm{b})}$ & $N^{c)}$ & $\begin{array}{l}\text { 单颗粒年 } \\
\text { 龄(Ma) }\end{array}$ & $\begin{array}{l}\text { 中值年 } \\
\text { 龄(Ma) }\end{array}$ & $P\left(\chi^{2}\right)^{\mathrm{d})}$ & P1 & $\mathrm{P} 2$ & P3 \\
\hline YH-04 & $190 \pm 5$ & $\begin{array}{c}\text { 下侏罗统 } \\
\left(J_{1 \mathrm{a}}\right)\end{array}$ & 细砂岩 & 2066 & $\begin{array}{l}42^{\circ} 7^{\prime} \\
83^{\circ} 24\end{array}$ & 668.0 & 391.6 & 88 & 18 & & 0 & & $\begin{array}{c}293.4 \pm 8.8 \\
(44.0 \%)\end{array}$ & $\begin{array}{c}399.5 \pm 10.1 \\
(27.0 \%)\end{array}$ \\
\hline YH-15 & $120 \pm 5$ & $\begin{array}{c}\text { 下白垩统 } \\
\left(\mathrm{K}_{\mathrm{lb}}\right)\end{array}$ & 粉砂岩 & 1852 & $\begin{array}{c}42^{\circ} 5^{\prime} 1.6^{\prime \prime} \mathrm{N} \\
83^{\circ} 23^{\prime} 15.3^{\prime \prime} \mathrm{E}\end{array}$ & 6 & 371.1 & 82 & 11 & $\begin{array}{c}266.8 \\
\pm 9.5\end{array}$ & 0 & $\begin{array}{c}177.5 \\
(28 .\end{array}$ & $\begin{array}{c}274.5 \pm 9.8 \\
(35.9 \%)\end{array}$ & $\begin{array}{c}362.2 \pm 11.9 \\
(35.6 \%)\end{array}$ \\
\hline YH-2 & $55 \pm 5$ & $\begin{array}{l}\text { 古新统 } \\
\left(\mathrm{E}_{1-2 \mathrm{~m}}\right)\end{array}$ & 细砂岩 & 1810 & $\begin{array}{l}42^{\circ} 4^{\prime} 18.2^{\prime \prime} \mathrm{N} \\
83^{\circ} 23^{\prime} 58.4^{\prime \prime} \mathrm{E}\end{array}$ & 668.8 & 409.5 & 81 & 103 & $\begin{array}{l}236.9 \\
\pm 10.1\end{array}$ & 0 & $\begin{array}{c}130.3 \pm 4.9 \\
(19.4 \%)\end{array}$ & $\begin{array}{c}232.6 \pm 5.0 \\
(51.2 \%)\end{array}$ & $\begin{array}{c}365.0 \pm 9.8 \\
(29.4 \%)\end{array}$ \\
\hline YH-24 & $30 \pm 3$ & $\begin{array}{c}\text { 渐新统 } \\
\left(\mathrm{E}_{2-3 \mathrm{~s}}\right)\end{array}$ & $\begin{array}{l}\text { 含砾砂 } \\
\text { 岩 }\end{array}$ & 1782 & $\begin{array}{c}42^{\circ} 4^{\prime} 6.7^{\prime \prime} \mathrm{N} \\
83^{\circ} 23^{\prime} 50.3^{\prime \prime} \mathrm{E}\end{array}$ & 671.6 & 413.5 & 132 & $105 \sim 466$ & $\begin{array}{c}276.5 \\
\pm 8.7\end{array}$ & 0 & $\begin{array}{r}120 . \\
(5 .\end{array}$ & $\begin{array}{c}207.9 \pm 2.4 \\
(40.8 \%)\end{array}$ & $\begin{array}{c}373.1 \pm 3.2 \\
(54.0 \%)\end{array}$ \\
\hline YH-2 & $18 \pm 3$ & $\begin{array}{c}\text { 中新统 } \\
\left(\mathrm{N}_{1 \mathrm{j}}\right)\end{array}$ & 细砂 & 1690 & $\begin{array}{c}42^{\circ} 3^{\prime} 0.6^{\prime \prime} \mathrm{N} \\
83^{\circ} 21^{\prime} 15.7^{\prime \prime} \mathrm{E}\end{array}$ & 675.1 & 347.6 & 119 & 52 & $\begin{array}{l}189.7 \\
\pm 7.0\end{array}$ & 0 & $\begin{array}{c}98.1 \pm 2.9 \\
(16.2 \%)\end{array}$ & $\begin{array}{c}175.6 \pm 2.6 \\
(49.7 \%)\end{array}$ & $\begin{array}{c}283.2 \pm 4.4 \\
(34.1 \%)\end{array}$ \\
\hline YH-3 & $1.5 \pm 0.3$ & $\begin{array}{c}\text { 第四系 } \\
(\mathrm{Q})\end{array}$ & 山े & 1503 & $\begin{array}{c}41^{\circ} 59^{\prime} 34.0^{\prime \prime} \mathrm{N} \\
83^{\circ} 19^{\prime} 0.7^{\prime \prime} \mathrm{E}\end{array}$ & & 3 & 29 & 331 & $\begin{array}{l}137.2 \\
\pm 13.0\end{array}$ & 0 & $\begin{array}{l}73.2 \pm 3.2 \\
(21.3 \%)\end{array}$ & $\begin{array}{c}116.5 \pm 3.4 \\
(47.6 \%)\end{array}$ & $\begin{array}{c}267.9 \pm 7.6 \\
(31.1 \%)\end{array}$ \\
\hline
\end{tabular}

a) 平均温度指数; b) 平均碱度指数; c) 锆石颗粒个数; d) 卡方检验值

1200 多颗锆石颗粒开展了形态学统计分析, 并按照频 率将它们投至锆石形态分布图上(图3), 可以看出这些 样品的锆石形态主要以 $P(P 1$ 或P2)、S、G等3种类型 为主. 在此基础上, 结合Pupin(1980)建立的公式(1)和 (2)分别计算了每个样品的平均碱度指数 $(I . \bar{A})$ 和平均 温度指数 $(I . \bar{T})($ 表 1$)$.

$$
\begin{aligned}
& I . \bar{A}=\sum_{I . A=100}^{800} I . A \times n_{I . A}, \\
& I . T=\sum_{I . T=100}^{800} I . T \times n_{I . T},
\end{aligned}
$$

式中, $I . A$ 为某一锆石形态对应的碱度指数, $n_{I . A}$ 为碱度 指数对应的某一锆石形态统计频率, I.T为某一锆石形 态对应的温度指数, $n_{I . T}$ 为温度指数对应的某一锆石形 态统计频率.

库车前陆盆地牙哈剖面中-新生界样品的 $I . \bar{A} 介$ 介于 $668.0 \sim 677.2, I . \bar{T}$ 介于 $347.6 \sim 413.5$. 将每个样品的平均 碱度指数和平均温度指数投点至母岩类型图上(图 $3 \mathrm{~g})$, 即得到这些碎屑锆石的源岩为碱性花岗岩，这与南天 山库尔楚和波孜果尔地区、中天山及伊犁地区出露的 碱性花岗岩相同(刘春花等, 2014; 秦切, 2017; Han和 Zhao, 2018; Huang等, 2020). 因此, 牙哈剖面中-新生界 碎屑物质应来源于天山地区.

\section{2 碎屑锆石U-Pb年龄分析结果}

为了更准确地识别库车前陆盆地东部牙哈剖面 中-新生界沉积物的物源区, 本文还对YH-04、YH-
15、YH-21、YH-24、YH-28等5块样品开展了碎屑锆 石U-Pb年龄测试与分析. 牙哈剖面下侏罗统样品YH04 的 111 个锆石 $\mathrm{U}-\mathrm{Pb}$ 年龄介于 $301 \sim 2454 \mathrm{Ma}$ (图 $4 \mathrm{a}$ ), 其 中介于 $380 \sim 470 \mathrm{Ma}$ 的锆石颗粒占比达 $83 \%$, 峰值年龄 为 418.6Ma. 对于下白严统样品YH-15, 除一个锆石U$\mathrm{Pb}$ 年龄为 $(1954 \pm 75) \mathrm{Ma}$ 外，其余 43 个锆石 $\mathrm{U}-\mathrm{Pb}$ 年龄介 于242 500Ma(图4b). 其中, U-Pb年龄介于 $242 \sim 250 \mathrm{Ma}$ 的锆石为 8 颗 $(18 \%)$, 峰值年龄为 $247.5 \mathrm{Ma}$; 介于 $271 \sim 308 \mathrm{Ma}$ 的锆石为 10 颗 $(23 \%)$, 峰值年龄为 $280.5 \mathrm{Ma}$; 介于 $381 \sim 500 \mathrm{Ma}$ 的锆石为 24 颗 (55\%), 峰值年龄为 443.3Ma. 古新统样品YH-21的 112 个锆石 $\mathrm{U}-\mathrm{Pb}$ 年龄介 于 $202 \sim 2770 \mathrm{Ma}$ (图 4c), 其中占比最多的两组为 $270 \sim 325 \mathrm{Ma}(17 \%$ ，峰值年龄为 $300 \mathrm{Ma})$ 和 $400 \sim 470 \mathrm{Ma}$ $(38 \%$, 峰值年龄为 $424.5 \mathrm{Ma})$. 对于渐新统样品 YH-24, 除 4 个锆石 U-Pb年龄大于 $500 \mathrm{Ma}$ 外, 其余 108 个锆石U$\mathrm{Pb}$ 年龄介于 263 461 Ma(图4d). 其中介于 $281 \sim 308 \mathrm{Ma}$ 的锆石为 32 颗 $(29 \%)$, 峰值年龄为 $299.2 \mathrm{Ma}$; 介于 409 461Ma的锆石为74颗(66\%), 峰值年龄为 $424.6 \mathrm{Ma}$. 中新统样品 $\mathrm{YH}-28$ 的 164 个锆石 $\mathrm{U}-\mathrm{Pb}$ 年龄介于 $238 \sim 2514 \mathrm{Ma}$ (图4e). 其中介于 $270 \sim 336 \mathrm{Ma}$ 的锆石为 22 颗(13\%), 峰值年龄为 $300.3 \mathrm{Ma}$; 介于 $400 ~ 447 \mathrm{Ma}$ 的锆 石为 76 颗(46\%), 峰值年龄为426.4Ma.

通过与天山及周缘山脉基岩锆石 $\mathrm{U}-\mathrm{Pb}$ 年龄对比 分析认为, 库车前陆盆地牙哈剖面中-新生界样品 $\mathrm{U}-\mathrm{Pb}$ 年龄介于202 250Ma的碎屑锆石可能来源于距离库车 地区较远的西昆仑、库鲁克塔格或北山地区(Liu等, 


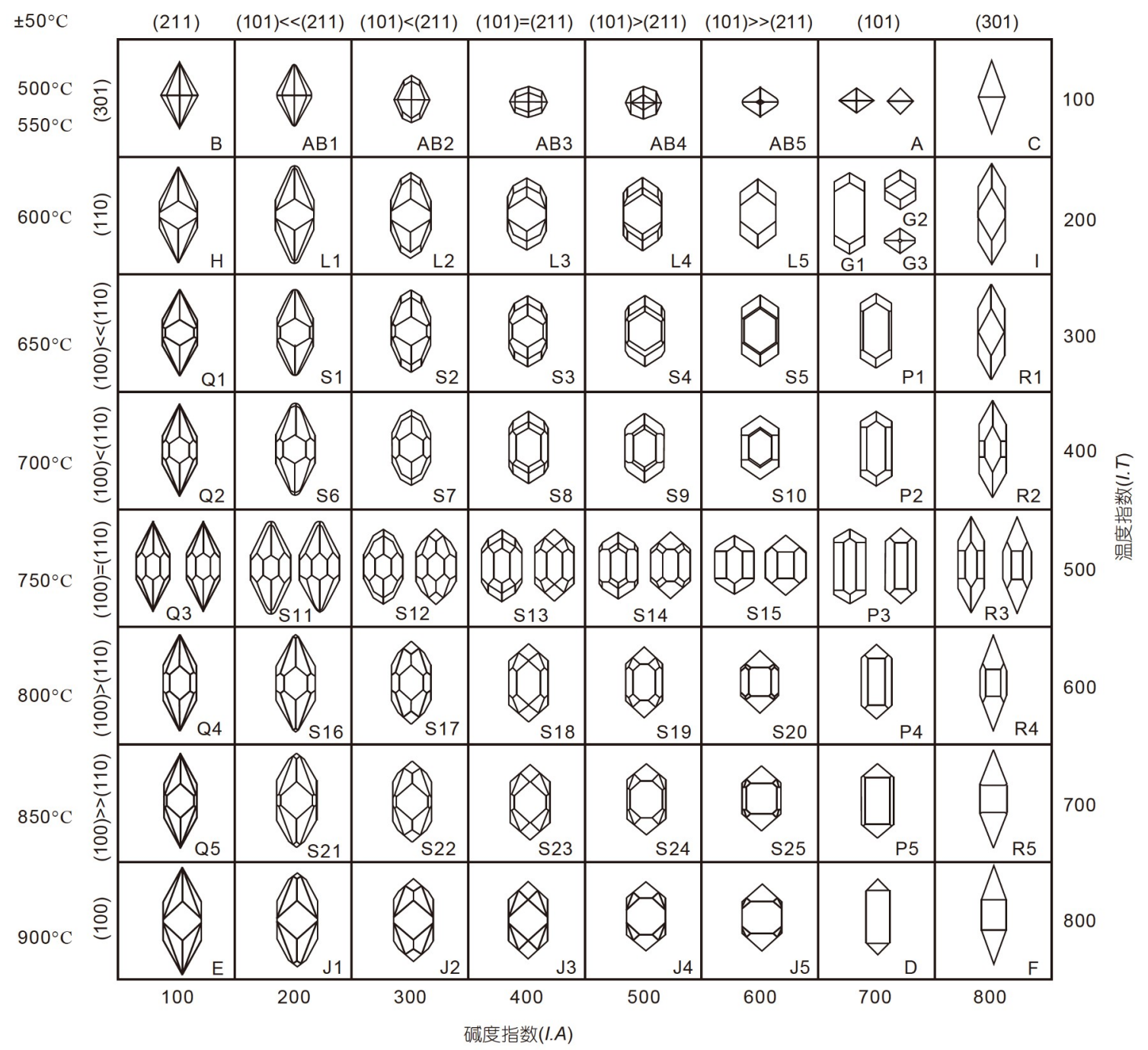

图 2 锆石形态划分图(Pupin, 1980)

2013; Han和Zhao, 2018); U-Pb年龄介于 270 330Ma的 碎屑锆石主要来源于南天山和中天山南部在早石炭 世-早二叠世时期受板块碰撞作用影响发育的多期花 岗岩体(Liu等, 2013; 秦切, 2017; Han和Zhao, 2018); U$\mathrm{Pb}$ 年龄介于 $380 \sim 470 \mathrm{Ma}$ 的碎屑锆石来源于中天山南部 和南天山北部, 这与中奥陶世-中泥盆世时期中天山板 块与南天山洋之间发生的构造增生作用及诱发的一系 列岩浆活动有关(Wang等, 2011; Han等, 2011; 秦切, 2017). 而U-Pb年龄大于 $500 \mathrm{Ma}$ 的锆石则来源于天山和 塔里木盆地北缘古老基底的再旋回沉积物, 由于占比 很少，这里不再赘述. 将所有样品的碎屑锆石 $\mathrm{U}-\mathrm{Pb}$ 年 龄汇总后发现(图4f)，270 330Ma(峰值年龄为300Ma)
和 $380 \sim 470 \mathrm{Ma}$ (峰值年龄为 $424.5 \mathrm{Ma}$ ) 的两组锆石颗粒 占绝对优势, 因此南天山和中天山南部是库车坳陷中新生代最主要的物源区. 值得注意的是, 与库车河剖面 样品相似(Li和Peng, 2010), 牙哈剖面下侏罗统也缺少 270 330Ma这组锆石U-Pb年龄, 这可能是由于南天山 及周缘在早侏罗世时期仍未出露早石炭世-早二叠世 发育的岩浆岩, 从而无法为库车前陆盆地提供物源.

\section{4 锆石裂变径迹(ZFT)年龄分析}

本文实测的 6 个样品 Z F T 中值年龄介于 $137.2 \sim 295.5 \mathrm{Ma}($ 表1), 均大于地层年龄, 且卡方检验值 

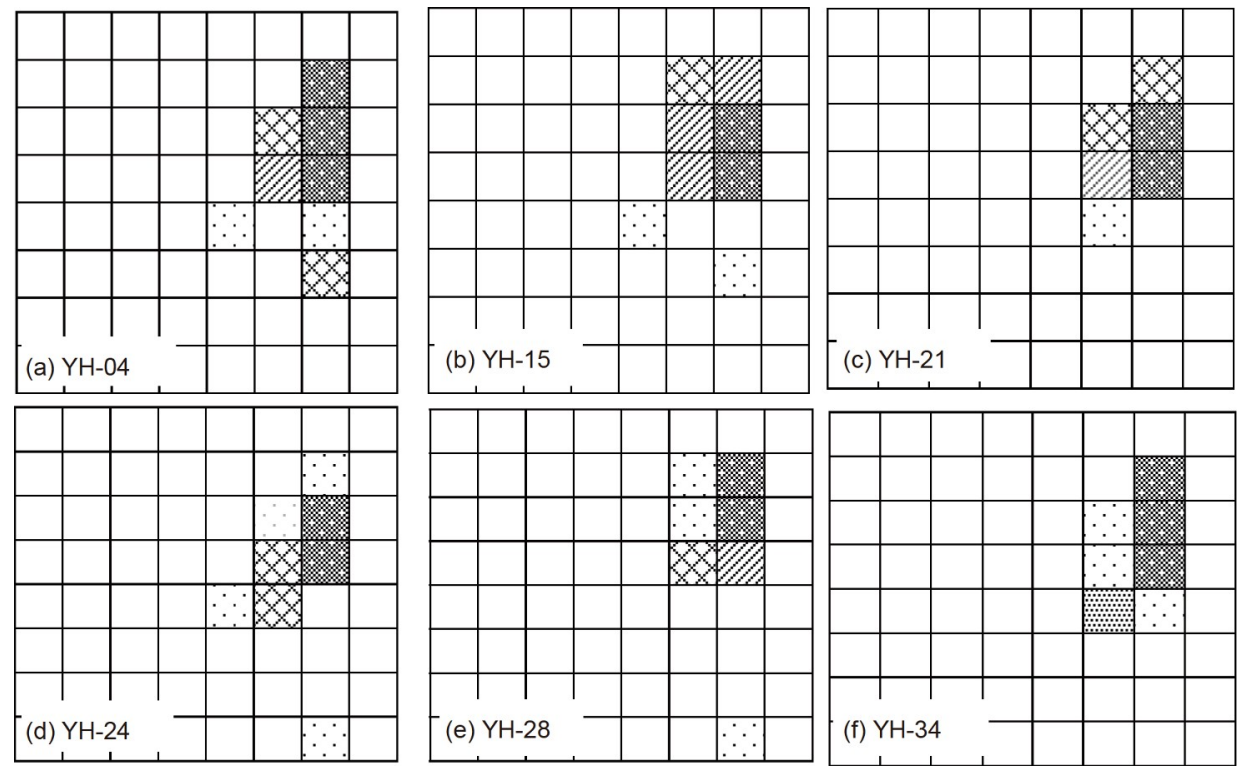

碱度指数 $(I . A)$
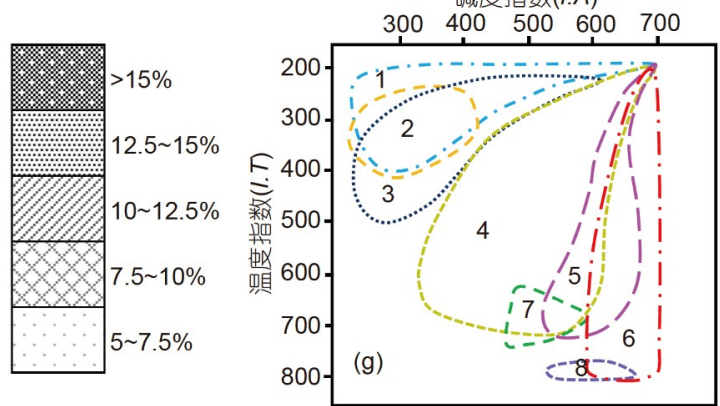

1-铅质浅色花岗岩

2-原地二长花岗岩和花岗闪长岩

3-侵入铝质二长花岗岩和花岗闪长岩

4- 钻碱性花岗岩

5 - 亚碱性幔源花岗岩

6-碱性花岗岩

7-大陆拉斑玄武岩系列花岗岩

8-海洋拉斑玄武岩系列花岗岩

\section{图 3 牙哈剖面中-新生界碎屑锆石形态统计及母岩识别图}

$P\left(\chi^{2}\right)$ 均为 0 , 表明牙哈剖面中-新生界沉积物在库车前 陆盆地沉积后未经历过高温重置，这些ZFT年龄记录 的仍是物源区 (中天山南部和南天山)热信息. 所有样 品的单颗粒ZFT年龄与 U含量呈非线性负相关性(图 5a)，表明辐射损伤对ZFT年龄分散性具有一定的影响. 从单颗粒ZFT年龄概率图可以看出(图5b), 随着沉积地 层变新, 更年轻的单颗粒ZFT年龄逐渐增多, 这说明物 源区自早侏罗世以来一直处于剥蚀状态，出露基岩热 年代学年龄也逐渐变小. 对于未重置样品, ZFT中值年 龄没有任何地质意义. 为了挖掘出混源单颗粒ZFT年 龄记录的物源区热信息，前人通常利用重分组方法对 实测数据进行处理和分析 (Galbraith和Green, 1990; Brandon等, 1998; Brandon, 2002; Vermeesch, 2018). 重分组方法不仅能够有效地识别出碎屑单颗粒ZFT年 龄来自几个物源区，而且还能揭示出每个物源区曾经
历过几期隆升冷却事件. 本次研究, 我们利用Galbraith 和Green(1990)提出的二项峰值拟合方法(Binomial “peaking-fitting” method)对每个样品的单颗粒ZFT年 龄进行重分组分析, 发现只有当每个样品被细分为三 组时, 其检验参数 $\left(\chi^{2}\right.$ 统计、 $\left.\mathrm{P}(\mathrm{F})\right)$ 才能达到最佳效果 (Brandon, 2002). 因此, 每个样品由新到老被细分为 P1、P2、P3等3组(表1)。这也表明亚哈剖面自侏罗纪 以来存在三个物源区(对应于 I 、 II 、III). 这三组ZFT 峰值年龄都具有随着沉积地层变新而逐渐变小的特 征，表明这三个物源区的隆升剥蚀过程具有阶段性和 递进性. 通过对重分组ZFT峰值年龄进一步统计分析, 识别出天山地区在泥盆纪-白严纪时期主要经历过 $399.5 \sim 362.2 、 293.4 \sim 267.9 、 232.6 \sim 175.6$ 和 130.3 73.2Ma等四期冷却事件. 而对于物源区新生代 以来的构造隆升过程，则需要建立ZFT年龄时滞演化 

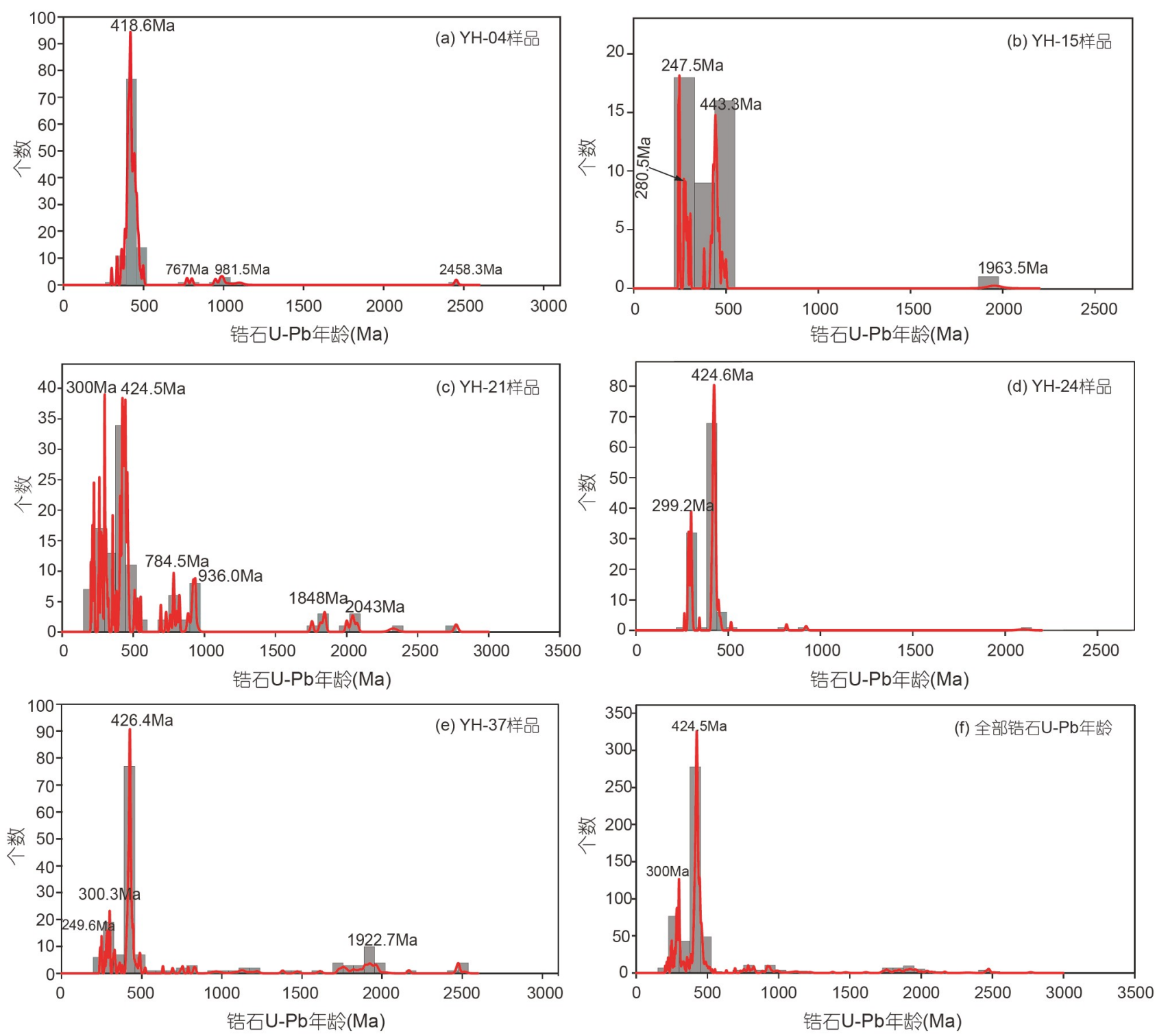

图 4 牙哈剖面中-新生界碎屑锆石 $\mathbf{U}-\mathbf{P b}$ 年龄分布直方图

模式进行研究.

\section{5 锆石裂变径迹年龄时滞演化模式}

当锆石矿物在沉积盆地沉积后未经历过部分或全 部退火，其锆石裂变径迹年龄与相应沉积地层年龄的 差值被定义为时滞(Garver等，1999). 本文结合重分组 ZFT年龄与沉积年龄建立了时滞演化模式(图6). 通常, 热年代学年龄演化曲线斜率与时滞曲线斜率具有三种 关系(Bernet等, 2001; 图7a): 当热年代学年龄曲线斜率
大于时滞曲线时, 表示山体处于快速隆升造山阶段 (constructive); 当热年代学年龄曲线与时滞曲线平行 时，表示山体处于稳态演化阶段(steady-state); 当热年 代学年龄曲线斜率小于时滞曲线时, 表明山体处于衰 退消减阶段(decaying). 如图6所示, P1组ZFT年龄演化 曲线显示物源区 I 经历了缓慢衰退(早侏罗世-渐新世) 和快速隆升(渐新世至今)两个阶段; P2组ZFT年龄演化 曲线显示物源区 II 经历了缓慢衰退(早侏罗世-早白严 世)-稳态演化(早白严世-渐新世)-快速隆升(渐新世至 今)等 3 个阶段; P3 组ZFT年龄演化曲线则显示物源 

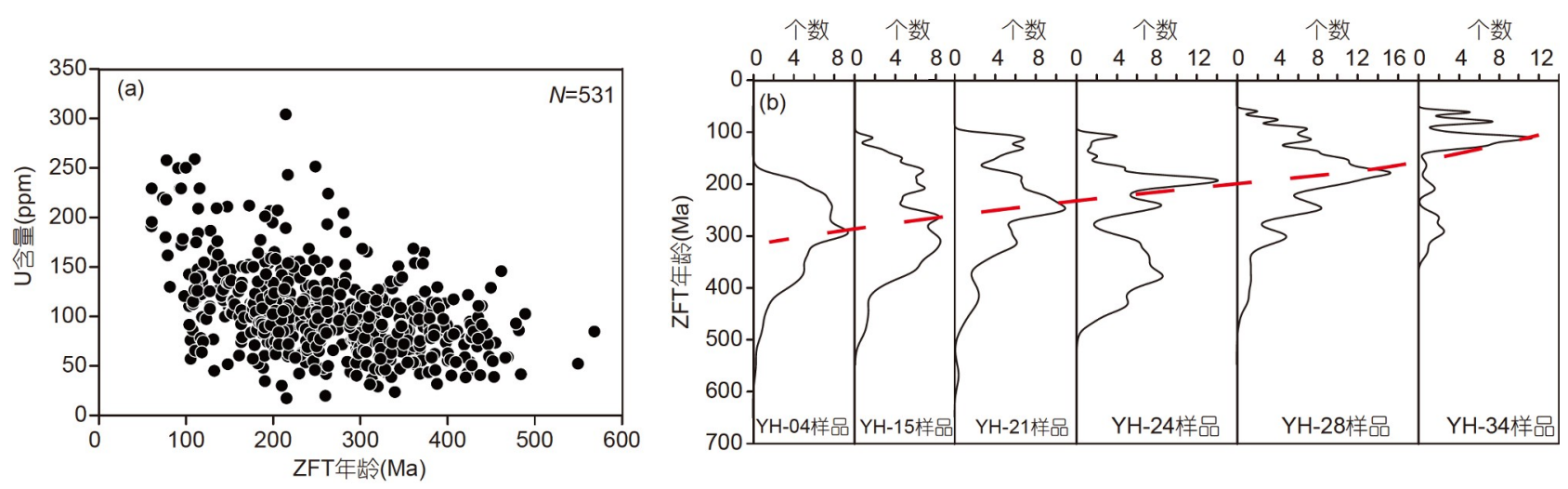

图 5 牙哈剖面中-新生界样品单颗粒ZFT年龄与 U含量关系(a)及其概率分布图(b)

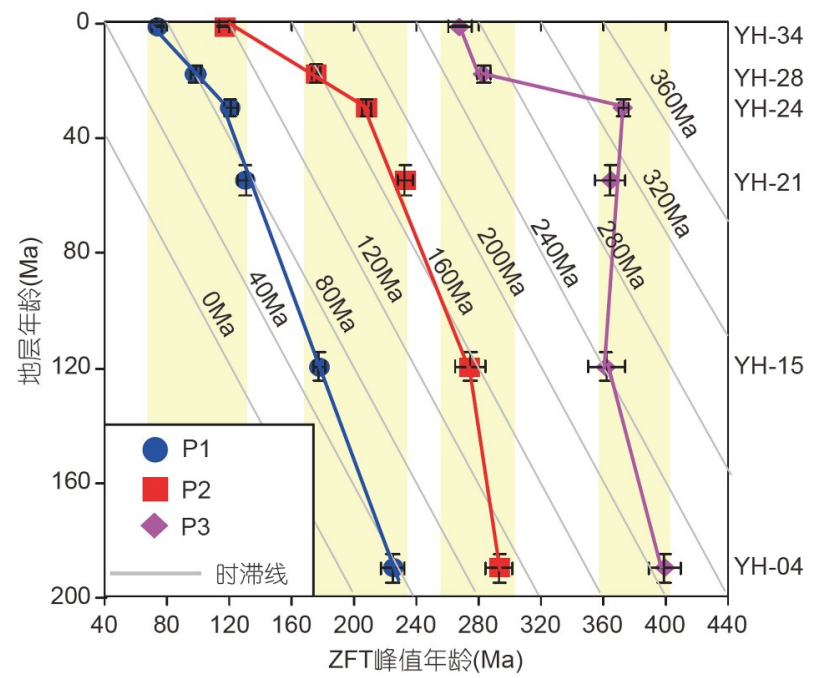

图 6 牙哈剖面ZFT峰值年龄与沉积年龄关系及时滞演化 模式

黄色条带表示四期隆升事件的时间跨度

区III经历了衰退(早侏罗世-渐新世)-快速隆升造山(渐 新世-中新世)-稳态演化(中新世至今)等三个阶段，其 中早期衰退阶段还可以进一步划分为缓慢衰退(早侏 罗世-早白严世)和快速衰退(早白严世-渐新世)两个亚 阶段. 尽管牙哈地区 3 个物源区自早侏罗世以来经历了 不同的构造演化阶段, 但总体上表现为早侏罗世-渐新 世为衰退-稳态阶段, 而渐新世以来处于造山-稳态 阶段.

利用时滞还可以计算山体剥蚀速率(Brandon等, 1998; Garver等，1999; Bernet和Garver，2005). 根据 Brandon等(1998)提出的自然辐射损伤模型，本文利用 Age2EDOT程序计算并绘制了时滞与剥蚀速率的转换 关系(图7b). 可以看出，时滞与剥蚀速率呈负相关性,
时滞越小, 剥蚀速率越大. 对于P1组(即物源区 I ), 早 侏罗世剥蚀速率为 $250 \mathrm{~m} \mathrm{Ma}^{-1}$, 至渐新世减小为 $90 \mathrm{~m}$ $\mathrm{Ma}^{-1}$, 之后剥蚀速率逐渐增大, 第四纪又增至 $110 \mathrm{~m}$ $\mathrm{Ma}^{-1}$; 对于P2组(即物源区 II), 早侏罗世剥蚀速率为 $80 \mathrm{~m} \mathrm{Ma}^{-1}$, 早白严世减小为 $55 \mathrm{~m} \mathrm{Ma}^{-1}$, 再至渐新世进 一步减小为 $50 \mathrm{~m} \mathrm{Ma}^{-1}$, 之后剥蚀速率增大, 第四纪增 至 $70 \mathrm{~m} \mathrm{Ma}^{-1}$; 对于P3组(即物源区III)，早侏罗世剥蚀 速率为 $38 \mathrm{~m} \mathrm{Ma}^{-1}$, 早白严世降至 $33 \mathrm{~m} \mathrm{Ma}^{-1}$, 至渐新世 进一步降至 $22 \mathrm{~m} \mathrm{Ma}^{-1}$; 之后剥蚀速率迅速增大, 中新 世增至 $30 \mathrm{~m} \mathrm{Ma}^{-1}$, 中新世-第四纪剥蚀速率不变.

\section{6 讨论}

\section{1 物源区识别}

如前所述，P1、P2、P3等三组重分组ZFT年龄揭 示出库车前陆盆地牙哈剖面中-新生代主要 有 I 、 II 、III三个物源区. 对于P3 组, 4 个介于 399 365Ma的ZFT年龄揭示出物源区III在泥盆纪时期 曾经历过一期快速冷却事件. 早期研究认为南天山形 成于晚石炭世-早二叠世(Xiao等，2004; Han等，2011; $\mathrm{Ge}$ 等, 2012), 因此南天山是无法经历该期冷却事件的. 据此推断P3组锆石矿物来源于中天山南部(图8), 与前 人认识一致( Li和Peng, 2010). 作为板块碰撞缝合带, 中 天山南部岩性以高压变质岩为主, 零星出露志留纪-早 泥盆世时期的花岗岩(朱志新, 2007). P1和P2组锆石应 来源于距离库车前陆盆地最近的南天山. 前人研究表 明，南天山的低温热年代学年龄具有由中部向东部逐 渐变老的趋势(Dumitru等, 2001; Chang等, 2021), 且南 天山东部发育一个古夷平面(Morin等，2019)，这些说 

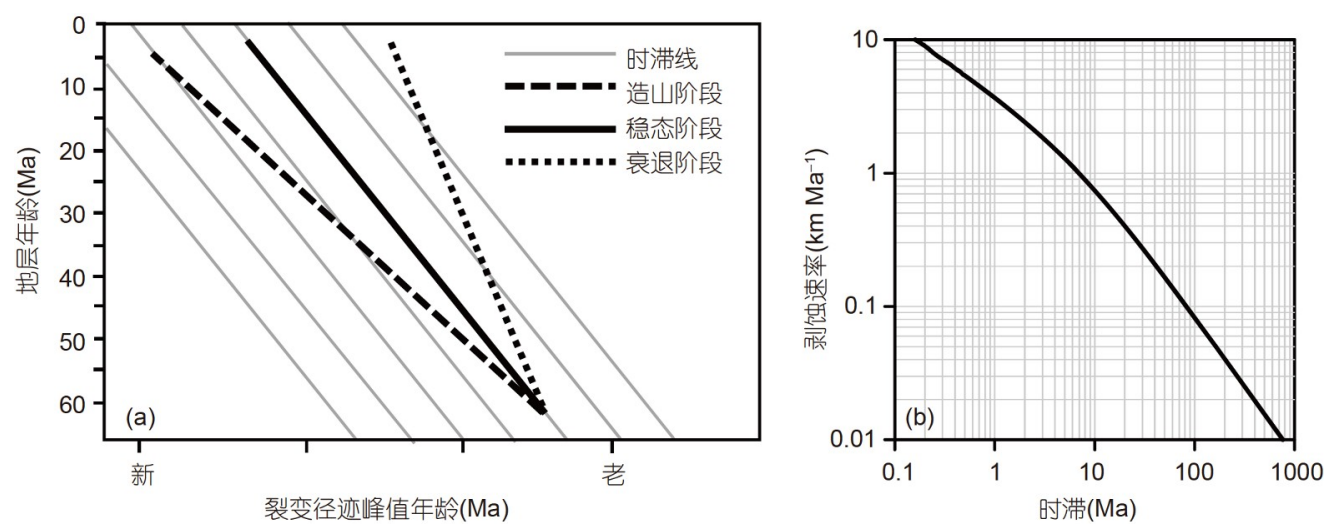

图 7 裂变径迹年龄时滞演化模式示意图(a)以及时滞与剥蚀速率关系图(b)

(a) 据Bernet等(2001); (b) 假设地温梯度为 $25^{\circ} \mathrm{C} \mathrm{km}^{-1}$

明南天山东部隆升和剥蚀速率相对较小. 同时, P2组 ZFT年龄占比也是最多的(表1), 这应该是近源供应便 利条件造成的. 综合以上认为, P1组锆石矿物来源于 南天山中部, 而较老的 $\mathrm{P} 2$ 组锆石矿物来源于南天山东 部(图8). 南天山中部主要发育晚奥陶世和志留纪时期 的陆源碎屑和碳酸盐岩, 部分地区出露早石炭世-早二 叠世或中奥陶世-中泥盆世时期的岩浆岩; 而南天山东 部以出露上志留统-石炭系陆源碎屑岩和古生代火成 岩为主(朱志新, 2007). 南天山中部和东部新生代以来 隆升速率存在差异的主要原因由两个: 一是印度板块 与欧亚板块南缘碰撞的远程效应引起的两个地区缩短 速率不同(Wang等, 2001); 二是南天山中部深部存在软 流圈上涌作用, 造成该地区快速隆升(Lei和Zhao, 2007; Chang等, 2021). 库车坳陷中-下侏罗统发育的“锆石-金 红石-电气石”重矿物组合表明天山地区在早-中侏罗 世时期构造活动较弱(此时南天山地势低)(李忠等, 2004), 中天山南部的剥蚀物质通过风力作用被搬运至 库车坳陷, 这一点被该地层高含量的 $\mathrm{Al}_{2} \mathrm{O}_{3}$ 证实(李忠 等, 2005). 自晚侏罗世以来, 盆一山之间的差异性隆升 为山间河道发育提供了条件(李忠等, 2005), 故库车坳 陷的沉积物质搬运方式以河流搬运为主.

\section{2 天山南部差异隆升过程}

结合锆石裂变径迹重分组年龄和时滞演化曲线, 本文揭示了天山南部自泥盆纪以来的多期构造隆升事 件. 库车前陆盆地牙哈剖面重分组ZFT年龄记录的中 天山南部经历的最早一期冷却事件发生在泥盆纪 (399 365Ma), 比南天山黑英山剖面白云母 ${ }^{40} \mathrm{Ar} /{ }^{39} \mathrm{Ar}$ 坪

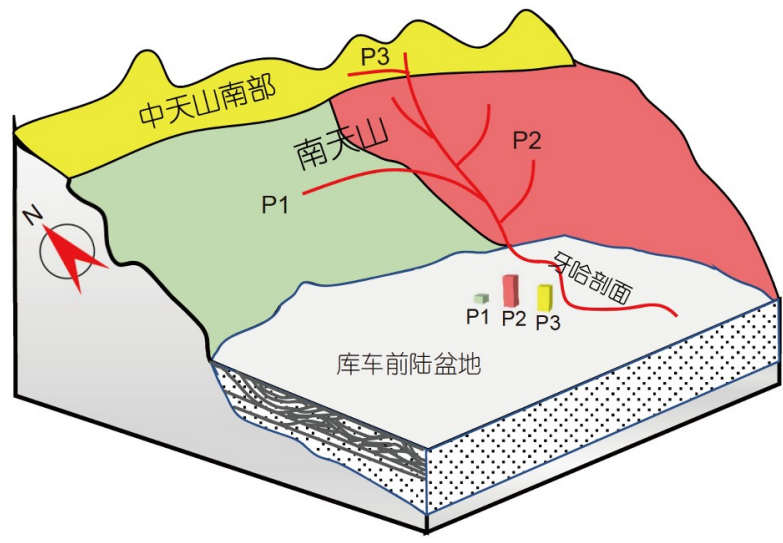

图 8 库车前陆盆地东部中-新生代物源分析模式图

年龄 (359 356Ma)揭示的冷却事件更早(Wang等, 2011). 另外, Glorie等 (2010) 通过分析钾长石 ${ }^{40} \mathrm{Ar} /{ }^{39} \mathrm{Ar}$

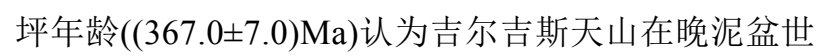
处于缓慢冷却状态. 泥盆纪时期, 南天山洋向北俯冲至 中天山板块下部, 不仅通过板块回转(slab rollback)作 用诱发中天山板块发生软流圈上涌形成大量岩浆岩 (Wang等, 2020), 而且使中天山南部浅部发生隆升剥蚀 (Tan等, 2019; Huang等, 2020), 从而造成部分层系锆石 矿物记录了该时期冷却事件. 早侏罗世, 这些层系锆石 矿物被剥蚀搬运至牙哈地区沉积下来.

库车前陆盆地牙哈剖面中-新生界P2和P3组ZFT 年龄揭示的二叠纪冷却事件(293.4 267.9Ma)曾被南 天山和中天山基岩区的 ${ }^{40} \mathrm{Ar} /{ }^{39} \mathrm{Ar}$ 、锆石 $(\mathrm{U}-\mathrm{Th}) / \mathrm{He}$ 、榍 石裂变径迹等热年代学参数研究报道(Carroll等, 1995; Dumitru等, 2001; de Jong等, 2009; Jolivet等, 2010; Yin 
等，2018), 并被认为是由塔里木板块与中天山板块碰 撞后的挤压和增生作用引起的. 该期冷却事件不仅使 南天山缝合带受右旋走滑作用影响发育大量糜棱岩 (de Jong等, 2009), 而且造成中亚地区二叠系与下伏地 层发育一个区域不整合面(Carroll等，1995). 需要指出 的是, P1、P2和 $\mathrm{P} 3$ 组中记录泥盆纪和二叠纪冷却事件 的部分单颗粒ZFT年龄也有可能是同时期的岩浆活动 在冷却过程中产生的. 由于受封闭温度差异的影响, 与 同时期发育的锆石 $\mathrm{U}-\mathrm{Pb}$ 年龄存在稍微差别. 由于该问 题并非本文研究重点, 不再赘述.

P 1 和 P 2 组揭示的南天山中三叠世-中侏罗世 (232.6 175.6Ma)快速隆升事件与库车前陆盆地北缘 的快速沉降作用具有很好的对应关系，反映了两者之 间良好的源-汇系统(Li和Peng，2010；Chang等，2017; Morin等，2018). 除南天山外，中天山、吉尔吉斯天 山、昆仑山、青藏高原等山体和塔里木盆地北缘柯坪 逆冲推覆带的低温热年代学年龄也记录了中三叠世中侏罗世这期快速冷却事件(Glorie等，2010；Cao等， 2015; Jolivet, 2015). 该期冷却事件普遍被认为与晚三 叠世-早侏罗世发生的羌塘地体和欧亚板块南缘碰撞 有关. 该碰撞事件不仅造成天山、塔里木盆地、准噶 尔盆地等地区的继承性古生界构造再次活化(Jolivet 等, 2010), 而且使塔里木盆地西南部发育前陆盆地, 柯 坪和巴楚地区演化为其前隆部位遭受剥蚀(Chang等, 2019). 需要指出的是，随着碰撞效应自早侏罗世以来 的逐渐减弱, 南天山处于衰退阶段, 且隆升速率逐渐降 低，正如本文ZFT年龄时滞演化曲线揭示的. Morin等 (2018)认为南天山在早-中侏罗世已被剥蚀至古平原化 状态.

库车前陆盆地碎屑ZFT年龄记录的南天山白严纪 冷却事件(130.3 73.2Ma)同样曾被中天山、吉尔吉斯 天山、昆仑山、塔里木盆地北缘、准噶尔盆地西缘等 地区的各种热年代学参数记录(Dumitru等，2001; Glorie等，2010; Jolivet等，2010; Glorie和De Grave, 2016；Yin等，2018). 这期冷却事件普遍被认为是由拉 萨地体与欧亚板块南缘碰撞造成的(Dumitru等，2001; Jolivet等，2010). Morin等(2019)和Jolivet(2015)根据热 年代学演化路径和地质资料认为中亚大部分地区在晚 侏罗世-早新生代发育一个古夷平面，且处于长期缓慢 隆升剥蚀状态. 由ZFT年龄揭示的南天山东部当时就 属于一个古夷平面(Morin等，2019)，处于缓慢冷却状
态，与时滞演化曲线揭示的情况相同. 而南天山中部 则可能处于构造活化区或受区域性走滑断裂调控(Jolivet等, 2010; De Grave等, 2013), 隆升速率相对较快. 由时滞演化模式揭示的渐新世(或中新世)以来的 快速冷却事件曾被中亚多个造山带及山前逆冲推覆带 的沉积相变、古地磁、热年代学等参数揭示出来(Yin 等, 1998; Dumitru等, 2001; Huang等, 2006; Jolivet等, 2010; Macaulay等, 2014; Chang等, 2017, 2019), 它是由 印度板块与欧亚板块南缘碰撞的远程效应造成的(Yin 等, 1998; Dumitru等, 2001). 南天山在晚新生代不仅快 速隆升遭受剥蚀(剥蚀速率达90 110 $\mathrm{m} \mathrm{Ma}^{-1}$ ), 而且受 构造挤压影响开始向南俯冲，使得塔里木盆地北缘形 成库车、柯坪、喀什等逆冲推覆带(Dumitru等，2001; Chang等，2019). 前人通过磷灰石裂变径迹分析认为 南天山自中新世以来的隆升剥蚀速率高达130 $200 \mathrm{~m} \mathrm{Ma}^{-1}$ (杨庚和钱祥麟, 1995; 杨树锋等, 2003), 比 本文结果略大. 早期研究普遍认为塔里木盆地北缘缩 短变形的时间为 25 20Ma(Yin等，1998; Dumitru等, 2001; Chang等, 2017), 比本文揭示南天山快速隆升的 时间稍晚，这可能暗示南天山的垂向变形比横向变形 更早. 一些学者利用牙哈剖面中新统样品的古地磁参 数揭示出南天山曾经历过 17 16Ma和 $11 \mathrm{Ma}$ 两期快速 隆升事件(Huang等, 2006; Charreau等, 2006), 而本文中 ZFT年龄时滞演化模式未有效地揭示出这两期事件, 可能是由于该时期样品数量有限而无法更精细地约束 南天山中新世以来的构造变形过程.

\section{3 碎屑热年代学时滞演化模式应用局限性}

碎屑热年代学时滞演化模式准确性既取决于实 测低温热年代学年龄, 也与样品的地层年龄相关. 锆 石裂变径迹年龄的测试精度主要取决于测试人员和 统计颗粒数. 为了得到更精确的重分组ZFT年龄, 在测 试过程中必须要细心, 同时统计尽量多的颗粒. ZFT年 龄演化曲线斜率还受样品地层年龄的影响. 由于研究 区地层年龄缺少古地磁年龄约束, 笔者在研究过程中 为每个样品地层年龄设置了 $5 \sim 10 \%$ 的误差，以便提高 分析的可靠性. Carrapa(2009)曾探讨过热年代学时滞 演化模式与造山楔逆冲样式之间的关系，但Bernet (2010)不赞同该观点. 这是因为不同的热年代学体系 对上地壳构造演化过程具有不同的敏感性，故在剥蚀 速率变化方面也具有不同的反映(Bernet, 2010). 另外, 
需要注意的是，造山带基岩在剥蚀过程中，其裂变径 迹样品总是经历未退火-部分退火-全部退火的演化过 程，对应的裂变径迹年龄演化模式在盆地内呈镜像关 系存在，可能会对时滞演化模式产生影响，这有待于 进一步研究.

\section{7 结论}

本文利用库车前陆盆地中-新生界碎屑锆石的形 态学特征和热年代学参数系统研究了南天山和中天山 南部的构造隆升史, 主要取得以下认识: (1) 碎屑锆石 形态以 $P(P 1$ 或 $P 2) 、 S 、 G$ 等3 种类型为主，相应的平均 温度指数和平均碱度指数分别为 $668.0 \sim 677.2$ 和 $347.6 \sim 413.5$, 同时其 $\mathrm{U}-\mathrm{Pb}$ 年龄集中于 $270 \sim 330$ 和 380 470Ma. 据此推断南天山和中天山南部发育的早 石炭世-早二叠世和中奥陶世-中泥盆世碱性花岗岩是 库车前陆盆地中-新生界碎屑锆石的物质来源; (2) 库 车前陆盆地中-新生界主要有中天山南部、南天山东 部、南天山中部等 3 个物源区, 它们曾经历过 $399.5 \sim 362.2 、 293.4 \sim 267.9 、 232.6 \sim 175.6$ 和 130.3 73.2Ma等4期隆升剥蚀冷却事件, 是由泥盆纪南 天山洋向北俯冲、早二叠世南天山洋闭合后的碰撞与 挤压、中生代㒸塘地体和拉萨地体与欧亚板块南缘碰 撞等构造活动造成的; (3) 南天山和中天山南部在侏罗 纪-渐新世和中新世至今分别处于衰退和快速隆升造 山(由印度板块与欧亚板块碰撞远程效应引起的)阶段, 其中南天山中部隆升速率最快, 达90 250 $\mathrm{m} \mathrm{km}^{-1}$.

致谢 感谢编委吴元保教授和两位审稿专家提出的宝贵 意见.

\section{参考文献}

陈国达, 黄建, 魏洲龄, 陈惠芳, 蔡嘉揂, 秦苏保, 谢建华. 1983. 天山 的中新生代大地构造问题. 地质论评, 29: 25-30

高俊, 钱青, 龙灵利, 张喜, 李继否, 苏文. 2009. 西天山的增生造山过 程. 地质通报, 28: 1804-1816

何登发, 周新源, 杨海军, 雷刚林, 马玉杰. 2009. 库车坳陷的地质结 构及其对大油气田的控制作用. 大地构造与成矿学, 33: 19-32 何光玉, 卢华复, 杨树锋, 李树新. 2004. 库车中新生代盆地沉降特征. 浙江大学学报(理学版), 31: 110-113

李双建, 王清晨, 李忠, 王道轩. 2006. 砂岩碎屑组分变化对库车坳陷 和南天山盆山演化的指示. 地质科学, 41: 465-478
李忠, 郭宏, 王道轩, 林伟. 2005. 库车坳陷-天山中、新生代构造转折 的砂岩碎屑与地球化学记录. 中国科学 $\mathrm{D}$ 辑: 地球科学, 35: 15-28 李忠, 王道轩, 林伟, 王清晨. 2004. 库车坳陷中-新生界碎屑组分对物 源类型及其构造属性的指示. 岩石学报, 20: 655-666

刘春花, 吴才来, 郜源红, 雷敏, 秦海鹏, 李名则. 2014. 南天山拜城县 波孜果尔A型花岗岩类锆石U-Pb定年及其 $\mathrm{Lu}-\mathrm{Hf}$ 同位素组成. 岩 石学报, 30: 1595-1614

秦切. 2017. 塔里木北缘-南天山地区古生代侵入岩年代学、成因及 构造意义. 博士学位论文. 北京: 中国地质大学. 1-162

汤良杰, 金之钧, 贾承造, 皮学军, 陈书平, 谢会文, 王子显. 2004. 库 车前陆褶皱-冲段带前缘大型盐推覆构造. 地质学报, 78: 17-25

杨庚, 钱祥麟. 1995. 库车坳陷沉降与天山中新生代构造活动. 新疆 地质, 13: 264-273

杨树锋, 陈汉林, 程晓敢, 肖安成, 周宇章, 卢华复, 贾承造, 魏国齐. 2003. 南天山新生代隆升和去顶作用过程. 南京大学学报, 39: 18

朱志新. 2007. 新疆南天山地质组成和构造演化. 博士学位论文. 北 京: 中国地质科学院. 1-216

Bernet M, Garver J I. 2005. Fission-track analysis of detrital zircon. Rev Mineral Geochem, 58: 205-237

Bernet M, Zattin M, Garver J I, Brandon M T, Vance J A. 2001. Steadystate exhumation of the European Alps. Geology, 29: 35-38

Bernet M. 2010. Tracing exhumation and orogenic wedge dynamics in the European Alps with detrital thermochronology: COMMENT. Geology, 38: e226

Brandon M T, Roden-Tice M K, Garver J I. 1998. Late Cenozoic exhumation of the Cascadia accretionary wedge in the Olympic Mountains, northwest Washington State. Geol Soc Am Bull, 110: 985-1009

Brandon M T. 2002. Decomposition of mixed grain age distributions using Binomfit. On Track, 24: 13-18

Cao K, Wang G C, Bernet M, van der Beek P, Zhang K X. 2015. Exhumation history of the West Kunlun Mountains, northwestern Tibet: Evidence for a long-lived, rejuvenated orogen. Earth Planet Sci Lett, 432: 391-403

Carrapa B, Di Giulio A, Mancin N, Stockli D, Fantoni R, Hughes A, Gupta S. 2016. Tectonic significance of Cenozoic exhumation and foreland basin evolution in the Western Alps. Tectonics, 35: 18921912

Carrapa B. 2009. Tracing exhumation and orogenic wedge dynamics in the European Alps with detrital thermochronology. Geology, 37: $1127-1130$

Carroll A R, Graham S A, Hendrix M S, Ying D, Zhou D. 1995. Late Paleozoic tectonic amalgamation of northwestern China: Sedimentary record of the northern Tarim, Northwestern Turpan, and southern Junggar Basins. Geol Soc Am Bull, 107: 571-594 
Chang J, Glorie S, Qiu N, Min K, Xiao Y, Xu W. 2021. Late Miocene (10.0 6.0 Ma) rapid exhumation of the Chinese South Tianshan: Implications for the timing of aridification in the Tarim Basin. Geophys Res Lett, 48: e90623

Chang J, Li D, Min K, Qiu N, Xiao Y, Wu H, Liu N. 2019. Cenozoic deformation of the Kalpin fold-and-thrust belt, southern Chinese Tian Shan: New insights from low-T thermochronology and sandbox modeling. Tectonophysics, 766: 416-432

Chang J, Tian Y T, Qiu N S. 2017. Mid-Late Miocene deformation of the northern Kuqa fold-and-thrust belt (southern Chinese Tian Shan): An apatite (U-Th-Sm)/He study. Tectonophysics, 694: 101113

Charreau J, Gilder S, Chen Y, Dominguez S, Avouac J P, Sen S, Jolivet M, Li Y, Wang W. 2006. Magnetostratigraphy of the Yaha section, Tarim Basin (China): $11 \mathrm{Ma}$ acceleration in erosion and uplift of the Tian Shan mountains. Geology, 34: 181-184

De Grave J, Glorie S, Buslov M M, Stockli D F, McWilliams M O, Batalev V Y, Van den haute P. 2013. Thermo-tectonic history of the Issyk-Kul basement (Kyrgyz Northern Tien Shan, Central Asia). Gondwana Res, 23: 998-1020

de Jong K, Wang B, Faure M, Shu L, Cluzel D, Charvet J, Ruffet G, Chen Y. 2009. New ${ }^{40} \mathrm{Ar} /{ }^{39} \mathrm{Ar}$ age constraints on the Late Palaeozoic tectonic evolution of the western Tianshan (Xinjiang, northwestern China), with emphasis on Permian fluid ingress. Int J Earth Sci-Geol Rund, 98: 1239-1258

Dumitru T A, Zhou D, Chang E Z, Graham S A, Hendrix M S, Sobel E R, Carroll A R. 2001. Uplift, exhumation, and deformation in the Chinese Tian Shan. In: Hendrix M S, Davis G A, eds. Paleozoic and Mesozoic Tectonic Evolution of Central Asia: From Continental Assembly to Intracontinental Deformation. Boulder: Geological Society of America Memoir. 71-99

Galbraith R F, Green P F. 1990. Estimating the component ages in a finite mixture. Int J Radiat Appl Instrument Part D Nucl Tracks Radiat Measure, 17: 197-206

Garver J I, Brandon M T, Roden-Tice M, Kamp P J J. 1999. Exhumation history of orogenic highlands determined by detrital fission-track thermochronology. Geol Soc Lond Spec Publ, 154: 283-304

Ge R, Zhu W, Wu H, Zheng B, Zhu X, He J. 2012. The Paleozoic northern margin of the Tarim Craton: Passive or active? Lithos, 142143: $1-15$

Glorie S, De Grave J, Buslov M M, Elburg M A, Stockli D F, Gerdes A, Van den haute P. 2010. Multi-method chronometric constraints on the evolution of the Northern Kyrgyz Tien Shan granitoids (Central Asian Orogenic Belt): From emplacement to exhumation. J Asian Earth Sci, 38: 131-146
Glorie S, De Grave J. 2016. Exhuming the Meso-Cenozoic Kyrgyz Tianshan and Siberian Altai-Sayan: A review based on lowtemperature thermochronology. Geosci Front, 7: 155-170

Han B F, He G Q, Wang X C, Guo Z J. 2011. Late Carboniferous collision between the Tarim and Kazakhstan-Yili terranes in the western segment of the South Tian Shan Orogen, Central Asia, and implications for the Northern Xinjiang, western China. Earth-Sci Rev, 109: 74-93

Han Y, Zhao G. 2018. Final amalgamation of the Tianshan and Junggar orogenic collage in the southwestern Central Asian Orogenic Belt: Constraints on the closure of the Paleo-Asian Ocean. Earth-Sci Rev, 186: $129-152$

Huang B, Piper J D A, Peng S, Liu T, Li Z, Wang Q, Zhu R. 2006. Magnetostratigraphic study of the Kuche Depression, Tarim Basin, and Cenozoic uplift of the Tian Shan Range, Western China. Earth Planet Sci Lett, 251: 346-364

Huang H, Wang T, Tong Y, Qin Q, Ma X, Yin J. 2020. Rejuvenation of ancient micro-continents during accretionary orogenesis: Insights from the Yili Block and adjacent regions of the SW Central Asian Orogenic Belt. Earth-Sci Rev, 208: 103255

Jolivet M, Dominguez S, Charreau J, Chen Y, Li Y, Wang Q. 2010. Mesozoic and Cenozoic tectonic history of the central Chinese Tian Shan: Reactivated tectonic structures and active deformation. Tectonics, 29: TC6019

Jolivet M. 2015. Mesozoic tectonic and topographic evolution of Central Asia and Tibet: A preliminary synthesis. Geol Soc Lond Spec Publ, 427: 19-55

Lei J S, Zhao D P. 2007. Teleseismic P-wave tomography and the upper mantle structure of the central Tien Shan orogenic belt. Phys Earth Planet Inter, 162: 165-185

Li Z, Peng S. 2010. Detrital zircon geochronology and its provenance implications: Responses to Jurassic through Neogene basin-range interactions along northern margin of the Tarim Basin, Northwest China. Basin Res, 22: 126-138

Li Z, Song W, Peng S, Wang D, Zhang Z. 2004. Mesozoic-Cenozoic tectonic relationships between the Kuqa subbasin and Tian Shan, northwest China: Constraints from depositional records. Sediment Geol, 172: 223-249

Liu D, Jolivet M, Yang W, Zhang Z, Cheng F, Zhu B, Guo Z. 2013. Latest Paleozoic-Early Mesozoic basin-range interactions in South Tian Shan (northwest China) and their tectonic significance: Constraints from detrital zircon U-Pb ages. Tectonophysics, 599: $197-213$

Macaulay E A, Sobel E R, Mikolaichuk A, Kohn B, Stuart F M. 2014. Cenozoic deformation and exhumation history of the Central Kyrgyz Tien Shan. Tectonics, 33: 135-165 
Malusà M G, Fitzgerald P G. 2020. The geologic interpretation of the detrital thermochronology record within a stratigraphic framework, with examples from the European Alps, Taiwan and the Himalayas. Earth-Sci Rev, 201: 103074

Morin J, Jolivet M, Barrier L, Laborde A, Li H, Dauteuil O. 2019. Planation surfaces of the Tian Shan Range (Central Asia): Insight on several 100 million years of topographic evolution. J Asian Earth Sci, 177: 52-65

Morin J, Jolivet M, Robin C, Heilbronn G, Barrier L, Bourquin S, Jia Y. 2018. Jurassic paleogeography of the Tian Shan: An evolution driven by far-field tectonics and climate. Earth-Sci Rev, 187: 286313

Pupin J P. 1980. Zircon and granite petrology. Contrib Mineral Petrol, 73: $207-220$

Qiu N, Chang J, Li J, Li W, Yun L, Li H. 2012. New evidence on the Neogene uplift of South Tianshan: Constraints from the (U-Th)/He and AFT ages of borehole samples of the Tarim basin and implications for hydrocarbon generation. Int J Earth Sci-Geol Rund, 101: $1625-1643$

Tan Z, Agard P, Monié P, Gao J, John T, Bayet L, Jiang T, Wang X S, Hong T, Wan B, Caron B. 2019. Architecture and P-T-deformation-time evolution of the Chinese SW-Tianshan HP/UHP complex: Implications for subduction dynamics. Earth-Sci Rev, 197: 102894

Vermeesch P. 2018. IsoplotR: A free and open toolbox for geochronology. Geosci Front, 9: 1479-1493

Wang B, Shu L, Faure M, Jahn B, Cluzel D, Charvet J, Chung S, Meffre
S. 2011. Paleozoic tectonics of the southern Chinese Tianshan: Insights from structural, chronological and geochemical studies of the Heiyingshan ophiolitic mélange (NW China). Tectonophysics, 497: 85-104

Wang Q, Li S, Du Z. 2009. Differential uplift of the Chinese Tianshan since the Cretaceous: Constraints from sedimentary petrography and apatite fission-track dating. Int J Earth Sci-Geol Rund, 98: 13411363

Wang Q, Zhang P Z, Freymueller J T, Bilham R, Larson K M, Lai X, You X, Niu Z, Wu J, Li Y, Liu J, Yang Z, Chen Q. 2001. Present-day crustal deformation in China constrained by global positioning system measurements. Science, 294: 574-577

Wang X S, Klemd R, Gao J, Jiang T, Zhang X. 2020. Early Devonian tectonic conversion from contraction to extension in the Chinese Western Tianshan: A response to slab rollback. Geol Soc Am Bull, 133: 1613-1633

Xiao W J, Zhang L, Qin K, Sun S, Li J. 2004. Paleozoic accretionary and collisional tectonics of the eastern Tianshan (China): Implications for the continental growth of Central Asia. Am J Sci, 304: 370-395

Yin A, Nie S, Craig P, Harrison T M, Ryerson F J, Xianglin Q, Geng Y. 1998. Late Cenozoic tectonic evolution of the southern Chinese Tian Shan. Tectonics, 17: 1-27

Yin J, Chen W, Hodges K V, Xiao W, Cai K, Yuan C, Sun M, Liu L P, van Soest M C. 2018. The thermal evolution of Chinese central Tianshan and its implications: Insights from multi-method chronometry. Tectonophysics, 722: 536-548

(责任编委: 吴元保) 